Ecology

Elsevier Editorial system(tm) for Fungal

Manuscript Draft

Manuscript Number: FUNECO-D-16-00203R1

Title: Intra-diurnal and daily changes in Didymella ascospore concentrations in the air of an urban site

Article Type: Original Research Paper

Keywords: pathogen; bioaerosol; asthma; exposure time; air quality; fungal ecology

Corresponding Author: Dr. Magdalena Sadyś, Ph.D.

Corresponding Author's Institution: Rothamsted Research

First Author: Magdalena Sadyś, Ph.D.

Order of Authors: Magdalena Sadyś, Ph.D.; Jonathan S West, Ph.D.

Abstract: Didymella sp. is a common plant pathogen affecting mainly cereal crops in countries with temperate climates, and its airborne spores are also a potential human allergen. A 5-year monitoring study was carried out at an urban site in the UK to establish the most likely exposure time in order to alert people sensitised to spores of this genus. Didymella ascospores occurred in air with a bimodal pattern, with peak concentrations occurring at $03: 00$ and 22:00. The majority of ascospores were observed from 20:30 to 07:30 according to a multivariate regression tree analysis. Similarly, circular tests indicated that the maximum hourly concentrations were found in the morning hours. The highest ascospore concentrations were observed in very humid conditions occurring after rainfall. The observations taken from an urban site were delayed in relation to the time of ascospore release previously reported from field sites. Thus, there is a high possibility of regional transport of ascospores in the atmosphere from remote sources. 


\title{
Intra-diurnal and daily changes in Didymella ascospore concentrations in the air of an urban site
}

\author{
Magdalena Sadyś ${ }^{1,2}$, Jonathan S. West ${ }^{2}$ \\ ${ }^{1}$ Institute of Science and the Environment, University of Worcester, \\ Henwick Grove, Worcester, WR2 6AJ, England \\ 2 Rothamsted Research, West Common, AL5 2JQ Harpenden, United Kingdom, \\ E-mail: magdalena.sadys@rothamsted.ac.uk, Tel. +44 (0)1582 938471
}

Dear Prof. Lynne Boddy,

This manuscript has been already reviewed (ref. FUNECO-D-16-00052) and I am currently resubmitting it once more, after a thorough revision. Although, the initial decision was negative, the associate editor Dr Anne Pringle and both reviewers indicated that this article could be reconsidered for a publication since the topic was of interest to the readers of Fungal Ecology.

Taking this opportunity, I would like to thank you, associate editor Dr Anne Pringle and two anonymous reviewers very much for the manuscript evaluation. I found most of the comments and suggestions very helpful and supportive. The suggested changes helped to improve this manuscript and I believe that it is now up to the standards required by the Fungal Ecology.

I also would like to bring to your kind attention that the authorship has been extended for Prof. Jonathan S. West, a plant pathologist with 20 years of experience and an English native speaker.

Didymella sp. is a common plant pathogen affecting mainly cereal crops in countries with temperate climates. Its' clinical importance as an aeroallergen was first reported in the 1970s in the UK. At present, although changes in the concentration of Didymella ascospores in the air are occasionally monitored, the number of reports on these ascospores is still very limited.

The importance of investigations of Didymella ascospore concentrations in the air is, in fact, the greater since the literature shows that their contribution to the overall fungal spectrum at various locations worldwide is the highest in temperate climates, and it may reach up to $20 \%$.

A 5-year survey was carried out at an urban site in order to establish the most likely exposure time in order to alert people sensitised to this type of spores. This aim has been accomplished by a comprehensive analysis using advanced statistical tools such as multivariate regression tree (MRT) models and circular statistics.

I would like to confirm that no substantial portion of the study has been published or is under consideration for publication elsewhere and that the submission for publication has been approved by the institutions where the work was carried out.

Yours sincerely, Dr Magdalena Sadyś 
Dr hab. Agnieszka Grinn-Gofroń /University of Szczecin/ agofr@univ.szczecin.pl

University of Szczecin

Department of Plant Taxonomy and Phytogeography

ul. Waska 13

71-415 Szczecin

Poland

Dr Rafael Tormo-Molina /Universidad de Extremadura/ ratormo@unex.es

Department of Plant Biology, Ecology and Earth Sciences

Faculty of Science

University of Extremadura

Avda Elvas s/n

06006 Badajoz

Spain

Dr Irene Câmara Camacho / University of Madeira / camire@uma.pt

University of Madeira

Life Science Competence Centre

Campus Universitário da Penteada

9000-390 Funchal

Portugal

Dr Michel Thibaudon/ RNSA, France/michel.thibaudon@wanadoo.fr

Réseau National de Surveillance Aérobiologique (RNSA)

11 Chemin de la Creuzille

69690 Brussieu

France 
Ref.: Ms. No. FUNECO-S-16-00248

Title: Intra-diurnal and daily changes in Didymella ascospore concentrations in the air of an urban site

Dear Lynne Boddy, Ph.D.

Editor-in-Chief

Fungal Ecology

We would like to thank you and two anonymous reviewers for the second manuscript evaluation. We found all the comments very supportive and encouraging.

We now feel that after applying changes suggested by all reviewers this manuscript has improved and hence, it will be matching the standards of the Fungal Ecology journal.

Furthermore, we would like to confirm that this work is original and has not been published elsewhere nor is it currently under consideration for publication elsewhere.

We have attached below my replies to the specific reviewer's comments as well as revised manuscript for your kind perusal.

Yours sincerely,

Dr Magdalena Sadyś

Dr Jonathan S. West

\section{Associate Editor' comments:}

I am pleased to send this back to you for minor revisions - there are some very useful edits and comments provided by the two reviewers and I hope you take advantage of these to make your final version as good as it can be! All the Best, Anne

Reply

We would like to thank the Associate Editor, Dr Anne Pringle, to evaluate the manuscript once more and given opportunity of the article re-submission to the Fungal Ecology journal. 


\section{Reviewer \#1}

\section{Comment 1}

I have read through the author's replies to reviewers and the revised manuscript. It is much improved over the first version, although I think there are a couple larger issues and a few minor issues that should be addressed.

Reply

We would like to thank the reviewer for taking the time to evaluate this manuscript, as well as for all suggested changes and comments.

\section{MAJOR ISSUES}

\section{Comment 2}

I can't quite understand how both of these statements can be true:

P9 9: The maximum spore concentrations consistently occurred at 22:00-23:00 and 04:00-05:00.

P9 20: All peaks were found between 05:00 and 10:00.

Reply

We would like to bring to the reviewer's kind attention that depending on selected test different results can be obtained. The actual peak concentrations, as they were observed in collected air samples, were presented in Fig. 3 and Fig. 4. The circular tests govern their own rights, and the mean angular test applied herein indicated the mean time of the ascospore peak occurrence in the air not the actual. It is also important to notice that calculated values of the angular deviation indicated a discrepancy of approximately 5 hours (Table 5). Thus, there is a lot of variability in the data. Our further examinations indicated a possible airborne transport of ascospores from remote sources which causes this variation. This has been now highlighted in the text to avoid confusion about discrepancy between the results.

\section{Comment 3}

In particular, looking at Figure 4 does not support the statement that the peaks are between $0500 \mathrm{~h}$ and $1000 \mathrm{~h}$. To me, the makes those statistical results suspect. When statistical results are not consistent with a visual assessment of the data, there needs to be a very clear assessment of why that might be. I don't see that here.

Reply

We would like to bring to the reviewer's kind attention that depending on selected test different results can be obtained. The actual peak concentrations, as they were observed in collected air samples, were presented in Fig. 3 and Fig. 4. The circular tests govern their own rights, and the mean angular test applied herein indicated the mean time of the ascospore peak occurrence in the air not the actual. It is also important to notice that calculated values of the angular deviation indicated a discrepancy of approximately 5 hours (Table 5). Thus, there is a lot of variability in the data. Our further examinations indicated a possible airborne transport of ascospores from remote sources which causes this variation. This has been now highlighted in the text to avoid confusion about discrepancy between the results. 


\section{Comment 4}

Figure 4 would be much easier to read if it were presented from noon to noon, rather than midnight to midnight. That way the high-spore period would not be broken up.

Reply

As suggested by the reviewer the data on the graphs have been now shown from noon to noon.

\section{Comment 5}

Fig 4 still uses the unfortunate abbreviation $\mathrm{s} \mathrm{m}^{-3}$.

Reply

This has been now corrected.

\section{Comment 6}

There are some very odd things about the figures in Fig 4 if you try to connect $24 \mathrm{~h}$ to $1 \mathrm{~h}$ (circularize the data). There are often very big jumps in the value of a line between $24 \mathrm{~h}$ and $1 \mathrm{~h}$, which are almost never seen in any other similar 1-h intervals. Are these correct?

Reply

The data once more was carefully evaluated and we can confirm that the results shown on the graphs are correct.

Following the reviewer's earlier comment, the data have been now given from noon to noon so the high-spore period is no longer broken up. This is relevant both for Fig. 3 and Fig. 4.

\section{MINOR ISSUES}

\section{Comment 7}

P4 36: Should this be "At present, Didymella spp. (hereafter Didymella) are considered among the major allergenic taxa ..."

Reply

Thanks to the reviewer for this remark. A suggested correction has been now applied in the text.

\section{Comment 8}

P8 57: This should read: Notably, the fungal spore season in 2006 began nearly a month earlier than in the following years.

\section{Reply}

Thanks to the reviewer for this remark. A suggested correction has been now applied in the text.

\section{Comment 9}

P9 29: write out multivariate regression tree, not the abbreviation MRT

Reply

Thanks to the reviewer for this remark. A suggested correction has been now applied in the text. 


\section{Comment 10}

P10 18: This should read ... without rainfall and days where rainfall was present

Reply

Thanks to the reviewer for this remark. A suggested correction has been now applied in the text.

\section{Comment 11}

Fig3 still uses the unfortunate abbreviation $\mathrm{s} \mathrm{m}^{-3}$

Reply

Thanks to the reviewer for this remark. A suggested correction has been now applied in Fig. 3.

\section{Comment 12}

There is no figure caption for the MRT in Fig 3.

Reply

Thanks to the reviewer for this remark. A suggested correction has been now applied in Fig. 3.

\section{Comment 13}

Fig5 is good to look at rain and spores, but there is still not really an attempt to differentiate between the effects of rainfall (or post rainfall) and high relative humidity. Are there high RH periods that are not following rainfall? Are spores lower than expected compared to after a rain?

\section{Reply}

While producing the Fig. 5 we have also selected all days, when the relative humidity was within the range of 85 to $100 \%(n=41)$. These days were cross checked for the presence and absence of rainfall. We found that only on a single occasion (11 Sep 2009) a relative humidity equal to $85 \%$ was not facilitated by the presence on rainfall. In remaining cases, the amount of rainfall that was recorded varied from 1 to $60 \mathrm{~mm}$. This information has now been highlighted in the manuscript.

\section{Comment 14}

The discussion is better, but it includes much too much simple review of the literature, with little real synthesis. I think it would be a better paper if the discussion were about half the length, with greater emphasis on putting these results into the context of other studies, rather than just a lot of description of assorted findings.

Reply

The manuscript has been previously reviewed by two independent reviewers. We do not know wherever the same reviewers provided their feedback in both rounds of the review process or not. Previously, the Reviewer \#1 wrote "The discussion is more of a review of the literature, and really needs to place the results of the study into the context of what others have found more directly." Following many specific comments the discussion has been thoroughly re-written. With regard to the current version of the discussion Reviewer \#2 did not indicate any need for correction. 


\section{Reviewer \#2:}

\section{Comment 1}

This manuscript is a revision of previous submission describing a five year study of Didymella ascospores in the atmosphere of Worcester. The authors address many of the concerns from both reviewers. There are still some issues which need to be addressed in the manuscript.

Reply

We would like to thank the reviewer for taking the time to evaluate this manuscript, as well as for all suggested changes and comments.

\section{Comment 2}

Page 4, lines 4-9: The authors describe Didymella ascospore release from other areas being in winter or spring. At Worcester, Didymella ascospores were primarily released in summer. The authors should address this difference in the discussion.

Reply

We have removed this passage of text and the reference to Gamliel-Atinsky et al., 2005 as that study was only reporting a single Didymella species occurring on chickpea debris, which was studied in a Mediterranean climate. Instead, we have cited Sadyś et al. (2016), which reports Didymella ascospores to be present all year in UK conditions with increased numbers in the summer and autumn.

\section{Comment 3}

Page 9, lines 16-20. The authors describe the results from the circular statistics which shows peak occurrence at 10 in the morning during 2006 (10:08) and 2010 (9:52). However, these times do not agree at all with the data shown in Figure 3 and 4, which show that 10 in the morning had consistently low concentrations. How do the authors explain this discrepancy? Why isn't this discrepancy mentioned in the discussion?

\section{Reply}

We would like to bring to the reviewer's kind attention that depending on selected test different results can be obtained. The actual peak concentrations, as they were observed in collected air samples, were presented in Fig. 3 and Fig. 4. The circular tests govern their own rights, and the mean angular test applied herein indicated the mean time of the ascospore peak occurrence in the air not the actual. It is also important to notice that calculated values of the angular deviation indicated a discrepancy of approximately 5 hours (Table 5). Thus, there is a lot of variability in the data. Our further examinations indicated a possible airborne transport of ascospores from remote sources which causes this variation. This has been now highlighted in the text to avoid confusion about discrepancy between the results.

\section{Comment 4}

Page 15, line 32: Why is "without a time lag" added to the maximum temperature description. This relates to the comments below for Figure 4. It appears that the authors were not using hourly meteorological conditions. This needs to be made clear. Explain why hourly spore concentrations are compared to daily meteorological parameters instead of hourly parameter. 
This manuscript constitutes a description of a part of the results that will be elaborated further in another paper. The ascospores of Didymella registered in Worcester originated from remote sources located further than $30 \mathrm{~km}$ from the sampling point. We know that the local weather has less impact on the actual ascospore production and release. Thus, extension of the analysis for the lagged local weather data would not provide additional valuable information.

The weather data throughout 4 out of 5 years was recorded at 5 min interval, which resulted in a very high number of records. The daily mean values were computed manually by the first author and this took more than 3 weeks to cover the period of interest. The computation of hourly data would need to be done in the same labour manner, and unfortunately we did not have a possibility to spend a month on just computing mean hourly records. If the weather station was set up correctly right at the beginning and calculated hourly mean values automatically, then of course we would use this resolution to match up with the fungal spore data. Unfortunately, at the beginning of the doctoral studies of the first author, the weather data have been already collected and there was not a possibility of changing the weather station settings.

The suitable clarifications in regard to this issue have been added in the caption of the Fig. 4 and in the Materials and Methods section.

\section{FIGURES}

\section{Comment 5}

Figure $1 \mathrm{C}$ : What is the arrow pointing at. There does not appear to be anything at the tip of the pointer. Please indicate in the figure legend, what is shown at the arrow.

Reply

The arrow in Fig. 1c points at hyaline Didymella ascospores, which are less visible than the coloured ascospores produced by different Didymella species. The caption of the Fig. 1c has been now revised.

\section{Comment 6}

Figure 3 a (top part) If the bars represent the cumulative levels over 5 years for each hour. These would be the spore index per hour. There should be NO units in a spore index. Delete the concentration units from the vertical axis.

\section{Reply}

The bars do not show the cumulative levels over 5 years for each hour. Each hour was treated as an individual record. Otherwise, we agree with the reviewer that the cumulative data should be shown without a unit on the graph.

\section{Comment 7}

This graph should be labelled as Fig 3a. The legend should indicate "Overall variations in cumulative Didymella ascospore hourly distribution...."

Figure $3 \mathrm{~b}$ (bottom part). This regression tree needs to be included in the figure legend and should be labelled as Fig $3 \mathrm{~b}$. This was brought up by one of the previous reviewers but was not corrected.

Reply 
Suggested changes have been now applied. The figure was split into Fig. 3a and Fig. 3b. The Fig. 3b has received a suitable caption.

\section{Comment 8}

Figure 4: The graphs in Figure 4 show hourly spore concentrations under various meteorological conditions. However, it appears that the authors are not using hourly meteorological data. This needs to be made clear in the figure legends as well as in the results.

Reply

The reviewer is right. The spore data was analysed at an hourly resolution, while their fluctuations shown in Fig. 4 were based on daily mean and daily accumulative (in case of rainfall) values for each examined meteorological parameter. This has been now clarified both in the Fig. 4 caption and in the manuscript.

\section{Comment 9}

Also, the units should be spores/m3 NOT s/m3. This was also brought up by one of the previous reviewers.

Reply

The axis label has been now revised in all figures following both reviewers suggestions. 
Research highlights:

- Exposure time to allergenic Didymella ascospores

- Impact of weather on the hourly changes in concentration in the air

- Comprehensive statistical evaluation of 5-year data collected in residential area 


\section{Intra-diurnal and daily changes in Didymella ascospore}

\section{concentrations in the air of an urban site}

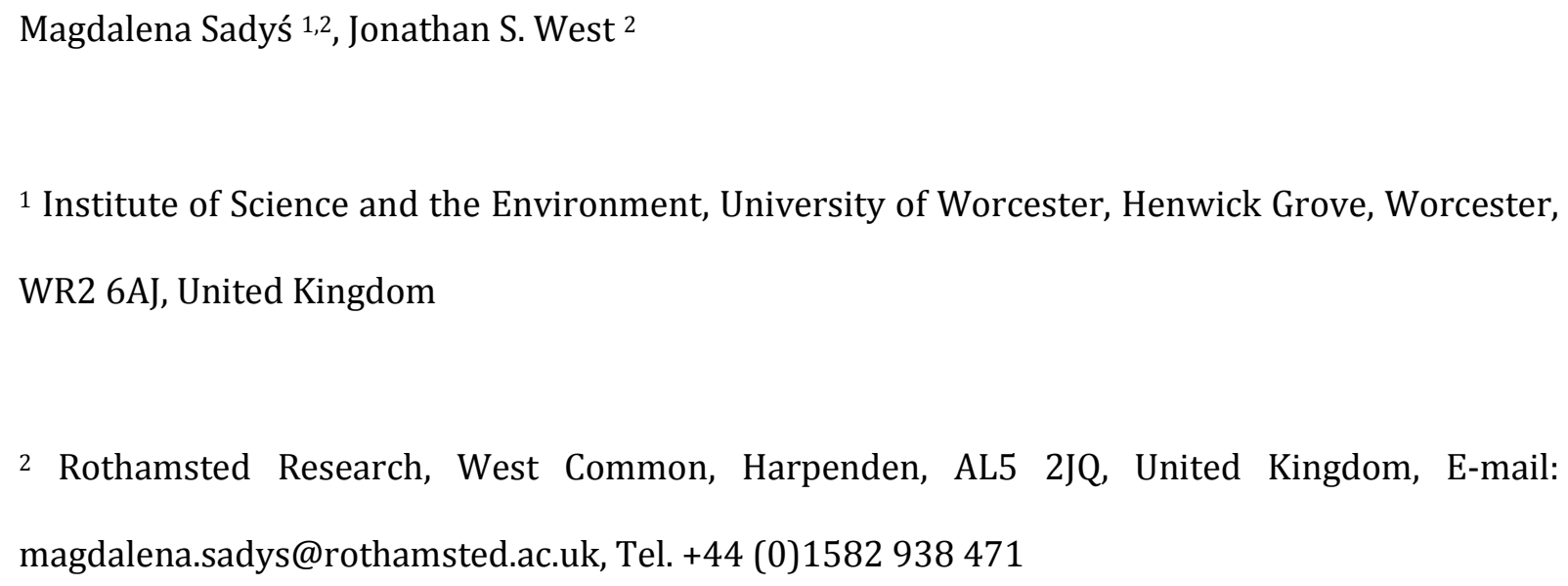

2 Rothamsted Research, West Common, Harpenden, AL5 2JQ, United Kingdom, E-mail: magdalena.sadys@rothamsted.ac.uk, Tel. +44 (0)1582 938471 


\begin{abstract}
Didymella species are common plant pathogens affecting mainly cereal crops in countries with temperate climates, and their airborne spores are also a potential human allergen. A 5-y monitoring study was carried out at an urban site in the UK to establish the most likely exposure time in order to alert people sensitised to spores of this genus. Didymella ascospores occurred in air with a bimodal pattern, with peak concentrations occurring at 03:00 and 22:00. The majority of ascospores were observed from 20:30 to 07:30 according to a multivariate regression tree analysis. Similarly, circular tests indicated that the maximum hourly concentrations occurred in the morning hours. The highest ascospore concentrations were observed in very humid conditions occurring after rainfall. The observations taken from an urban site were delayed in relation to the time of ascospore release previously reported from field sites. Thus, there is a high possibility of regional transport of ascospores in the atmosphere from remote sources.
\end{abstract}

\title{
Keywords
}

pathogen; bioaerosol; asthma; exposure time; air quality; fungal ecology; 


\section{Introduction}

The genus Didymella is a group of widespread saprotrophic and pathogenic fungi, with around 75 described species (Kirk et al., 2004). Allitt (1986) identified 6 hyaline species in air samples collected in Cambridge, UK (Fig. 1). Didymella is a causal agent of diseases such as ascochyta leaf scorch (D. exitialis), ascochyta blight of chickpea (D. rabiei), ascochyta blight of pea (D. pinodes), spur blight on red raspberries (D. applanata), and ray blight of chrysanthemum (D. chrysanthemi) (Burchill and Beever, 1975; Trapero-Casas et al., 1996; Fox, 2005; Salam et al., 2011; Nicolaisen et al., 2014;). Although the occurrence of Didymella species has been reported in many countries around the world, e.g. in Australia, Korea, New Zealand, this fungus is frequently observed in countries with temperate climates (Frankland and Gregory, 1973; Jackson, 1984; Corden and Millington, 1994; Cromey et al., 2004;Khan et al., 2013; O'Connor et al., 2014; Oh et al., 2014). Cereal crops, such as wheat (Triticum sativum), barley (Hordeum vulagare), oats (Avena sativa) and rye (Secale cereale), are mostly affected by Didymella exitialis and D. phleina (Cromey et al., 1994; Stefansson and Hallsson, 2011; AHDB, 2015). In the UK, cereal crops cover $>3$ million ha and constitute $51 \%$ of the total agricultural area (DEFRA, 2015). The 2015 wheat harvest for the UK was 16.44 million tonnes, while for barley and oats, 7.37 and 0.80 million tonnes, respectively (DEFRA, 2015). Didymella exitialis is considered to be a minor pathogen of wheat but infection is common and contributes to yield loss (AHDB, 2015).

The Phylum Ascomycota is characterised by the production of sexual spores (ascospores) in saclike asci formed in ascomata. Within each ascus, karyogamy is followed by meiosis and then mitosis, which usually results in the formation of eight haploid ascospores. In Didymella genus, the ascomata type is a pseudothecium (fruit body with two layer asci organised irregularly). In addition, pycnidia (spherical fruit bodies that produce conidia, by asexual reproduction) start to form in autumn and mature at the beginning of spring (Burchill and Beever, 1975). Airborne ascospores constitute the primary inoculum source of disease, while conidia, which are 
disseminated by rain splash, are of secondary importance epidemiologically, and rarely disperse

At the beginning of the 1970s, a link between high ascospore counts of Didymella exitialis in the air and asthmatic symptoms of two patients, who lived in the vicinity of barley fields, was first reported (Frankland and Gregory, 1973). Further investigation revealed that 12 out of 100 patients showed sensitisation to Didymella exitialis extracts using a skin prick test. Subsequently, Harries et al. (1985), Packe and Ayres (1985) and Alderman et al. (1986) confirmed that Didymella exitialis was responsible for late summer asthma, though Morrow Brown and Jackson (1985) did not find a similar correlation. At present, Didymella spp. (hereafter Didymella) are considered among the major allergenic taxa in the United Kingdom causing respiratory tract diseases (Newson et al., 2000; AHDB, 2015).

The importance of investigations of Didymella ascospore concentrations in the air is greater than previously supposed, since the literature shows that their contribution to the overall airborne fungal spectrum at various locations worldwide is the highest in temperate climates (D'Amato and Spieksma, 1995). This contrasts with Mediterranean (Gonianakis et al., 2005; Akgül et al., 2016), subtropical (Sousa et al., 2016) and tropical climates (Khandelwal, 2001; Hasnain et al., 2005; Quintero et al., 2010), where Didymella ascospores were either rarely observed or not detected at all in collected air samples. The necessity of studying diurnal variations in fungal spore concentration has been raised since it was noticed that a periodic unexpected "cloud of fungal spores" may trigger allergic reactions in sensitised people (Pakpour et al., 2015), resulting in hospitalisation, or even death (Asthma UK, 2016). Increases in hourly Didymella ascospore concentrations are often observed during or shortly after thunderstorms, followed by 
rising numbers of asthma-related hospital admissions (Packe and Ayres, 1985; Pulimood et al., 2007; Thibaudon et al. 2014). Knowing the time of greatest concentration of allergenic fungal spores in the air can help patients in planning their outdoor activities, to reduce their exposure to fungal spores.

The current study aimed to determine when peak concentrations of Didymella ascospores in the air are likely to occur and what meteorological conditions must be met to facilitate these spore events. Spore and weather data were collected at an urban site in the UK throughout a 5-y period.

\section{Materials and methods}

\subsection{Air sampling}

A 7-d volumetric spore trap (Hirst, 1952; West and Kimber, 2015) was operated continuously from 1 Jan 2006 to 31 Dec 2010, to measure hourly and daily mean fungal spore concentration at Worcester, UK $\left(52^{\circ} 11^{\prime} \mathrm{N}, 2^{\circ} 14^{\prime} \mathrm{W}\right)$. The air sampler was placed on a flat rooftop at a height of $10 \mathrm{~m}$ above ground level. Airborne particles, including Didymella ascospores, were trapped by impaction on the surface of a sampling tape coated with an adhesive, fastened tightly to a rotating drum inside the air sampler. The drum rotated past the $2 \mathrm{~mm}$ wide air intake at $2 \mathrm{~mm} \mathrm{~h}$ ${ }^{1}$ and sampled particles in air at a rate of $10 \mathrm{~L} \mathrm{~min}^{-1}$. Drums with new collection tape were changed each week on Thursdays at 09:00 UTC. The sampling tape was cut into $20 \mathrm{~mm} \times 48 \mathrm{~mm}$ long sections (corresponding to a $24 \mathrm{~h}$ period), mounted using lactophenol incorporating Cotton Blue stain and secured with coverslips and nail varnish, which prevented damage to the samples by the loss of moisture.

Fungal spores were identified to the genus level using a light microscope under $\times 400$ magnification and counted along one longitudinal transect with a field width of $0.54 \mathrm{~mm}$. Hourly 
and daily mean data resolutions were applied. Didymella ascospores have either biconic or an ellipsoid shape with a size range of $12-18 \mu \mathrm{m} \times 4-6 \mu \mathrm{m}$ (Fig. 1). They can be either hyaline or yellowish in colour with a smooth or rough wall surface, and a characteristic single septum in the middle (Dennis, 1981; Zhang et al., 2012). Photographs of Didymella ascospores were taken using an AxioCam Mrc5 camera, attached to the microscope. Software enclosed by the manufacturer (Carl Zeiss Vision $\mathrm{GmbH}$ ) enabled their further processing. To get hourly counts, a printed grid with $2 \mathrm{~mm}$ intervals was placed under each examined microscope slide. Finally, the concentration of ascospores was calculated using the formula described in Lacey and West (2006) and expressed as a number of spores per cubic metre of air [spores $\mathrm{m}^{-3}$. The data analysis and control were performed under the ISO/IEC 17025.

Weather data were obtained from the weather station (WeatherLink 9.0 Vantage Pro2 station) co-located with the air sampler at the University of Worcester. All meteorological parameters (rainfall, relative humidity, maximum temperature, wind speed) were recorded from 00:00 to 23:59 according to UTC local time. Daily mean (maximum temperature, relative humidity, wind speed) and daily accumulative (rainfall) values were used in this study.

\subsection{Statistical testing}

The fungal spore seasons were calculated using the "90\% method" introduced by Nilsson and Persson (1981). The season started when $5 \%$ of the accumulative sum of daily mean spore concentration was exceeded, and finished when $95 \%$ was surpassed. Calculating the season in this way prevented an artificial extension of the fungal spore seasons length (Jäger, 2003). Additionally, this technique enabled the removal from the data of observations on days when old spores occurred that could be present in the air due to re-suspension processes. 
Preliminary data screening included examinations of data distribution using 3 normality tests

(Kolmogorov-Smirnov test, Kolmogorov-Smirnov test with Lilliefors correction and ShapiroWilk test), and detection of the linearity or lack thereof between all examined variables by visual inspection of the scatter graphs. The selection of three normality tests was based on the fact that each of them is characterised by a different sensitivity (Ghasemi and Zahediasl, 2012). As the normality of the fungal spore seasons was examined using three tests, the distribution of spores was understood as normal, when all three tests resulted in $p \geq 0.05$. Non-parametric tests were applied since the preliminary screening revealed a non-normal distribution of the spore data.

The annual differences in the daily mean and hourly mean distribution of Didymella ascospores were examined using the Kruskal-Wallis test. The sign test was used to investigate whether there was any statistically significant difference in ascospore distribution on rainy $(\geq 0.20 \mathrm{~mm})$ and dry $(0 \mathrm{~mm})$ days (Salam et al., 2011). The impact of hourly changes in precipitation, relative humidity, maximum temperature and wind speed on ascospore inter-diurnal distribution were studied using the Friedman test. All selected meteorological parameters were divided into 4 levels, upon preliminary data screening, and examined against spore counts. In addition, the impact of rainfall on ascospore release was studied by selecting 7-d long events, which occurred within the fungal spore seasons indicated by the "90\% method" described above. Three variations were tested, i.e., (a) 4 dry days followed by 3 rainy days, (b) 3-4 rainy days followed by 3 dry days, and (c) a single rainy day preceded and proceeded by 3 dry days. Daily mean values were calculated based upon 5 events for each tested variation.

Considering a $24 \mathrm{~h}$ period as one full rotation $\left(360^{\circ}\right)$, circular statistical tests enabled indication of the time, when on average the maximum ascospore concentration in the air was observed (regardless the impact of weather). Hours with maximum concentration were selected from a pool of days indicated by the fungal spore season ranges. In cases where the same value of maximum spore concentration was repeated within a $24 \mathrm{~h}$ period, e.g. at 02:00, 19:00 and 23:00, 
all those hours were used for the purpose of this analysis. Each hour was then expressed as an angle in degrees. Further steps of this analysis, aiming to obtain a mean angle value, were described in Zar (1984). The mean angle expressed as a function of sine and cosine was converted back to the time format ( $\mathrm{h} \mathrm{min}$ ). In addition to this, a range of a circular distribution of data as the smallest arc (an angular dispersion), was calculated (Zar, 1984).

Finally, the multivariate regression tree analysis was performed in order to indicate the time of the day when the highest ascospore concentrations were observed (Grinn-Gofron and Strzelczak, 2009). For this reason, all spore seasons were pooled together. Results of this test were supplementary to the results computed using circular analyses.

All statistical analyses were performed with the aid of Statistica Statsoft (2012), GenStat (v. 17), R (v. 2.9.2) and Microsoft Excel (2016).

\section{Results}

\subsection{Time analysis in relation to high spore counts}

The seasonal dynamics showed variations in Didymella ascospore occurrence during the study period (Fig. 2). Inter-annual differences using both daily mean and hourly mean values were confirmed by the Kruskal-Wallis test (Table 1). The longest season was in 2006 while the shortest season occurred in the following year (Fig. 2). Notably, the fungal spore season in 2006 began nearly a month earlier than in the following years. With the exception of 2007, the midpoint of the season happened repeatedly in August, between the $2^{\text {nd }}$ and the $19^{\text {th }}$ day of the month (Fig. 2).

Temporal variations of Didymella ascospore fluctuations based on real observations showed a double peak pattern (Fig. 3). The maximum spore concentrations consistently occurred at 22:00 
and 03:00. The majority of Didymella ascospores were observed in 2007 and 2008 (Fig. 4A). In 2,000 spores $\mathrm{m}^{-3}$. Results of the circular analysis showed that the mean time of the maximum ascospore concentration tended to occur in the morning hours rather than in the evening (Table 2). All peaks were found between 05:00 and 10:00 ( $\pm 2.5 \mathrm{~h})$. Significant decreases in Didymella spore concentrations oscillating around 400 spores $\mathrm{m}^{-3}$ were found at 10:00 and 16:00, respectively (Table 2).

The multivariate regression tree analysis showed a great difference in the number of ascospores per cubic metre of air depending on the time of the day (Fig. 3). The first important border hour that had been determined was 07:30. The average concentration of ascospores before 07:30 (right cluster) was 1,850 spores $\mathrm{m}^{-3}$ (based upon 2,737 h). The left cluster was further split into two smaller clusters, and the border hour determined by the regression tree was 20:30. The average concentration of ascospores before 20:30 was equal to 424 spores $\mathrm{m}^{-3}$ (results based upon 5,083 h). The average concentration of ascospores after 20:30 was equal to 1,440 spores $\mathrm{m}^{-3}$ (based upon $1,564 \mathrm{~h}$ ).

\subsection{Impact of changing weather conditions}

Didymella ascospore concentration increased on rainy days compared to dry days (Fig. 4B). The occurrence of a double peak pattern early in the morning and early at night was evident on rainy days while dry days had a less pronounced elevation in ascospore numbers from late night until early morning. The maximum concentration of Didymella spores on rainy days was recorded at 05:00 and 23:00, and varied between 2,800 spores $\mathrm{m}^{-3}$ and 4,000 spores $\mathrm{m}^{-3}$. A sudden decrease in ascospore concentration to 460 spores $\mathrm{m}^{-3}$ was observed from 10:00 to 17:00 (Fig. 4B). On dry days the maximum ascospore concentration peaked once at $06: 00$ reaching 1,400 spores $\mathrm{m}^{-}$ 3 , and the minimum concentrations of $<300$ spores $\mathrm{m}^{-3}$ were found from 10:00 to 20:00 (Fig. 4B). 
The sign test confirmed the statistically significant differences between days without rainfall and

Elevated ascospore concentrations were observed after the presence of rainfall (Fig. 5). This was true for each selected case and for all tested variations, i.e., dry days followed by rainy days, rainy days followed by dry days, and during rainy days preceded and proceeded by 3 dry days. Days of prolonged precipitation yielded 3-fold higher ascospore concentrations (Figs 5A and 5B) in comparison with single rainy days occurring in the middle of a dry week (Fig. 5C). The ascospore concentrations decreased to $<100$ spores $\mathrm{m}^{-3}$ usually either on the first or second day after the rainfall (Figs 5B and 5C). However, a prolonged dry period resulted in no ascospore release (Fig. 5A). Two mm of rain was sufficient to trigger ascospore discharge after a dry period (Fig. 5C).

Classifying the amount of rainfall in $24 \mathrm{~h}$ into four categories $(0<n \leqslant 5 \mathrm{~mm}, 5<n \leqslant 10 \mathrm{~mm}$, $10<n \leqslant 15 \mathrm{~mm}$ and $15<n \leqslant 20 \mathrm{~mm}$ ) showed that the highest hourly concentration of Didymella ascospores occurred between $10<$ and $\leqslant 15 \mathrm{~mm}$ (Fig. 4C). These amounts of rainfall favoured dispersal of Didymella ascospores, which peaked at 22:00 with a concentration approaching maximum 5,700 spores $\mathrm{m}^{-3}$ but generally there was no clear effect of different amounts of rain on ascospore concentrations (Fig. 4C) compared to effects of no rain (Fig. 4B). The Friedman test confirmed that there was a statistically significant difference in the inter-diurnal distribution of ascospores (Table 4).

The lowest relative humidity (n), which occurred within the study period, was $40 \%$. All days when the relative humidity was within the range of 85 to $100 \%(n=41)$ were cross examined for the presence or absence of the rainfall. Only on a single occasion (11 Sep 2009) was a high relative humidity equal to $85 \%$ was not facilitated by the presence of rainfall. In the remaining cases, the amount of rainfall that was recorded varied from 1 to $60 \mathrm{~mm}$. The spore concentration 
analysed by relative humidity class peaked at 23:00 with a concentration above 6,500 spores $\mathrm{m}^{-}$

Didymella ascospores were significantly affected by maximum temperature (Fig. 4E). A double peak pattern was observed, and a peak according to data analysed by temperature, recorded at 22:00 with a spore count of approximately 5,000 spores $\mathrm{m}^{-3}$. A statistically significant difference between maximum temperature and diurnal distributions of Didymella for all individual years and 5-y averages was indicated by the Friedman test (Table 4).

The Didymella concentration decreased when wind speed exceeded a threshold of $3 \mathrm{~m} \mathrm{~s}^{-1}$ (Fig. 4). The highest concentrations were found at low wind speeds up to $2 \mathrm{~m} \mathrm{~s}^{-1}$, with peaks observed between $04: 00$ and 06:00, and from 22:00 to 23:00. The Friedman test confirmed that there was a statistically significant difference in the diurnal pattern of Didymella ascospores associated with changes in wind speed; these dependencies were observed in all years under investigation (Table 4).

\section{Discussion}

Sadyś et al. $(2015 ; 2016)$ examined the distribution of the 20 most common allergenic fungal spores in the air of Worcester (UK) from 2006 to 2010. Among the examined group, the overall contribution of Didymella ascospores varied annually between $2.02 \%$ (2010) and 20.56\% (2008) reaching a 5-y mean value of $8.4 \%$. More discussion on the seasonal variations in Didymella ascospore concentrations can be found in these reports (Sadyś et al., 2015; 2016). Data collected at Worcester exhibited a double peak pattern in Didymella with peaks observed at 03:00, and then again at 22:00 (Fig. 3). This contrasts with other studies, including 
measurements taken in a chickpea field near Córdoba (Spain), which showed a single peak distribution of Didymella rabiei ascospores between 14:00 and 16:00 (Trapero-Casas et al., 1996), while the studies of Gonianakis et al. (2005) and Akgül et al. (2016) did not find any distinct pattern in Didymella ascospores due to very low counts and episodic appearance in the air of Irakleion (Crete, Greece) and Gaziantep (Turkey), respectively.

Release mechanisms of ascospores are numerous and they vary from species to species. To date there is no specific information available for the ascospore liberation mechanism in Didymella genus. Many ascomycetes release their ascospores in an explosive manner. This results in increased chances for long distance dispersal by shooting spores beyond the boundary layer of stagnant air near the surface of the fruit bodies (Ingold, 1971). The distance at which ascospores can be discharged vary from 0.2 to $40 \mathrm{~cm}$ (Ingold, 1979). Fungi that belong to the Class of Dothideomycetes, including genera such as Didymella and Leptosphaeria, usually produce a double-wall type of ascus, with a thin elastic inner wall and rigid outer wall. The inner wall is very sensitive to wetness which it absorbs immediately causing excessive swelling. This causes the outer wall to burst and the ascospores are pushed out under pressure through an apical pore at the top of the fruit body (Ingold, 1971). It has been estimated that approximately $85 \%$ of mature ascospores in Mycosphaerella musicola can be released within 10 min after wetting the surface of infected leaves (Meredith, 1973).

Results confirmed that the presence of rainfall had the most significant impact on the diurnal distribution of hourly Didymella spore counts out of all examined meteorological parameters (Fig. 4). A similar positive impact of rainfall was noted by Trapero-Casas et al. (1996), who caught $94 \%$ of airborne Didymella rabiei spores using a Hirst trap during rainy days in a 5-y survey. Measurements of airborne Mycosphaerella (=Didymella) ascospore concentrations, taken in a field with wheat stubble in New Zealand, showed that large numbers of ascospores were released within a few hours after rainfall (Hampton, 1975). When no rain occurred, ascospores 
were trapped regularly within a $6 \mathrm{~h}$ period (00:00-06:00). Similarly, Corden and Millington (1994) found the majority of ascospores trapped during dry days were trapped at night (04:0005:00). If there was a substantial amount of rainfall, then ascospore concentrations peaked earlier, at 18:00. Hirst (1953) suggested that the nocturnal ascospore release from perithecia on dry days was caused by dew formation at night. In contrast, in Kraków (Poland) ascospore concentrations showed a more distinctive diurnal pattern during dry days rather than on rainy days (Stępalska and Wołek, 2009), while in London (UK) Harries et al. (1985) noted a clear diurnal pattern for both dry and rainy days. At Worcester, maximum concentrations were apparent, both at 05:00 and 23:00 (Fig. 4), whereas in Kraków a single peak occurred between 03:00 and 04:00 (Stępalska and Wołek, 2009). The disparity between dry and rainy days was also found by Stępalska and Wołek (2009), but after a 3-y period of sampling ( $z=-2.75, p=0.03)$. A small increase in numbers of ascospores was also seen by Stępalska and Wołek (2009) after dusk, from 17:00 to 00:00 during rainy days.

The dominant influence of rainfall on ascospore concentrations was also seen for ascospore release patterns in Leptosphaeria maculans and L. biglobosa (Huang et al., 2005). Harries et al. (1985) recorded a spore count of Didymella exitialis equal to 7,000 spores $\mathrm{m}^{-3}$ at Harpenden, when $4 \mathrm{~mm}$ of rain was recorded, $4 \mathrm{~h}$ after the occurrence of a thunderstorm. Furthermore, Trapero-Casas et al. (1996) stated that discharge of Didymella rabiei ascospores was more dependent on the presence of rainfall rather than the amount of rain based on 5-y observations. Hernández Trejo et al. (2012) examined the ascospore concentration of 19 taxa and determined that the role that rainfall and relative humidity play in the ascospore discharge were species specific. To illustrate this, it has been established empirically in a field that $0.2 \mathrm{~mm}$ of rain yielded the maximum ascospore discharge in Rhaphidophora graminis, previously Ophiobulus graminis (Meredith, 1973). 
The very strong association between high Didymella spore counts with relative humidity conditions (85-100\%) in our study, confirms observation in Poland (Stępalska and Wołek, 2005). Richardson (1996) reported that a sudden increase in Didymella spore concentration $\left(>4,000\right.$ spores $\mathrm{m}^{-3}$ at $\left.05: 00\right)$ in the air at Edinburgh (Scotland) was explained by an increase in relative humidity up to $95 \%$. In our study, spore production was highly correlated with humidity, however, $97 \%$ of high humidity days also had high precipitation. Other previously published reports analysed the correlation between presence of ascospores in the air and relative humidity, but without excluding the impact of the rainfall (e.g. von Wahl and Kersten, 1991; Stępalska et al., 2012). These reports showed, however, weak associations of ascospore release with relative humidity.

Significant Didymella ascospore concentrations were associated with a temperature range of $10^{\circ} \mathrm{C}-15^{\circ} \mathrm{C}$, similarly to the observations from Edinburgh, where Didymella spore concentrations varying between 1,001 and 5,000 spores $\mathrm{m}^{-3}$ were found at $11^{\circ} \mathrm{C}$ (Richardson, 1996). Similarly, von Wahl and Kersten (1991) reported a range of $10-20^{\circ} \mathrm{C}$ temperature associated with the detection of ascospores in the air of Essen-Bredeney. Packe and Ayres (1985) suggested that higher temperatures, up to 4 days before the occurrence of the thunderstorm, could accelerate maturation of ascospores that were ready to be released under higher relative humidity conditions. This was further confirmed by Corden and Millington (1994) in Derby (UK). The observations of infections of cucurbits caused by Didymella bryoniae in the greenhouses led to the conclusion that the optimum temperature for infection varied between $16^{\circ} \mathrm{C}$ and $24^{\circ} \mathrm{C}$ (Miller et al., 2001).

The impact of wind speed on diurnal and daily concentrations of Didymella ascospores is less frequently studied (von Wahl and Kersten, 1991), and then only the strength of the correlation, but not the limitation threshold tends to be reported (Stępalska et al., 2012; Martínez Blanco et al., 2016). Nevertheless, Martínez Blanco et al. (2016) found an inversely proportional 
relationship between Didymella and wind speed in Montevideo (Uruguay), Stępalska et al. (2012) observed a directly proportional association in Szczecin (Poland) and no impact at all in Kraków (Poland). In our study, lower ascospore release when wind speeds were above $3 \mathrm{~m} \mathrm{~s}^{-1}$ presumably reflects higher wind speeds reducing the humid boundary layer close to moist substrata, which would inhibit spore release. The peak of spore release on dry days tended to be in the early morning, which is when the wind is lightest and the relative humidity is highest.

To date, a study of Trapero-Casas et al. (1996) is one of the very few reports that provide information on the Didymella ascospore release time directly measured at the inoculum source. Other studies, which examined dispersal of this pathogen (Salam et al., 2011; Davidson et al., 2013) did not apply volumetric air sampling and thus are not comparable with our study. Kaiser and Küsmenoglu (1997) reported a dispersal distance of D. rabiei for several kilometres from the inoculum source, which at typical wind speeds equal to $2 \mathrm{~m} \mathrm{~s}^{-1}$ would delay arrival in the city centre by an hour. Arrival of spores from a distant source within a regional scale $(<1,000 \mathrm{~km})$ cannot be excluded, as many spores such as those of Alternaria sp. and soybean rust (Phakopsora pachyrhizi, P. meibomiae) spores can travel long distances (e.g. Isard, 2005; Fernández Rodríguez et al., 2015). Since, there is an obvious discrepancy between the timing of ascospore release reported by Trapero-Casas et al. (1996), the current survey and other similar reports (Corden and Millington, 1994; Stępalska and Wołek, 2009), it can be concluded that ascospore transport via the air currents took a place in our study.

\section{Conclusion}

Intra-diurnal distributions of Didymella ascospores were constantly found on rainy days during a 5-y survey carried out at Worcester, UK. Ascospores were present in the air from the end of June until mid-September with peak concentrations occurring in mid-August. Several statistical tests indicated both relative humidity $(85-100 \%)$ and rainfall $(10-15 \mathrm{~mm})$ as the most important 
factors influencing high ascospore concentrations in the air of an urban site, with the former

\section{Acknowledgements}

This study was funded by the University of Worcester and conducted within the framework of the doctoral studies of the first author. Special thanks go to Dr Andrew M. Reynolds and anonymous reviewers for the manuscript evaluation. Last but not least we would like to thank Prof. Lynne Boddy for the final output of this article.

\section{References}

AHDB, 2015. The Encyclopaedia of Cereal Diseases. Available from: http://cereals.ahdb.org.uk/media/185607/g41-the-encyclopaedia-of-cereal-diseases2015-branding-.pdf

Alderman, P.M., Sloan, J.P., Basran, G.S., 1986. Asthma and thunderstorms. Arch. Emerg. Med. 3, $260-262$.

Akgül, H., Yılmazkaya, D., Akata, I., Tosunoğlu, A., Bıçakçı, A., 2016. Determination of airborne fungal spores of Gaziantep (SE Turkey). Aerobiologia 32, 441-452.

Allitt, U., 1986. Identity of airborne hyaline, one-septate ascospores and their relation to inhalant allergy. Trans. Br. Mycol. Soc. 87, 147-154. 
Asthma UK, 2016. Asthma facts and statistics [Online]. Available from: https://www.asthma.org.uk/about/media/facts-and-statistics/ [Accessed 27 February 2016].

Burchill, R.T., Beever, D.J., 1975. Seasonal fluctuations in ascospore concentrations of Didymella applanata in relation to raspberry spur blight incidence. Ann Appl. Biol. 81, 299-304.

Corden, J.M., Millington, W.M., 1994. Didymella ascospores in Derby. Grana 33, 104-107.

Cromey. M.G., Ganev, S., Braithwaite, M., Boddington, H.J., 1994. Didymella exitialis on wheat in New Zealand. New Zeal. J. Crop Hort. 22, 139-144.

Cromey, M.G., Butler, R.C., Mace, M.A., Cole, A.L.J., 2004. Effects of the fungicides azoxystrobin and tebuconazole on Didymella exitialis leaf senescence and grain yield in wheat. Crop Prot. $23,1019-1030$

D’Amato, G., Spieksma, F.T.M., 1995. Aerobiologic and clinical aspects of mould allergy in Europe. Allergy 50, 870-877.

Davidson, J.A., Wilmshurst, C.J., Scott, E.S., Salam, M.U., 2013. Relationship between ascochyta blight on field pea (Pisum sativum) and spore release patterns of Didymella pinodes and other causal agents of ascochyta blight. Plant Pathol. 62, 1258-1270.

DEFRA, 2015. Farming Statistics. Final crop areas, yields, livestock populations and agricultural workforce at June 2015 - United Kingdom. Available from:

https://www.gov.uk/government/uploads/system/uploads/attachment_data/file/4863 26/structure-jun2015final-uk-17dec15.pdf

Dennis, R.W.G., 1981. British Ascomycetes, Strauss \& Cramer GmbH, Hirschberg.

Fernández Rodríguez, S., Sadyś, M., Smith, M., Tormo-Molina, R., Skjøth, C.A., Maya-Manzano, J.M., Silva-Palacios, I., Gonzalo-Garijo, Á., 2015. Potential sources of airborne Alternaria spp. spores in South-west Spain. Sci. Total Environ. 533, 165-176.

Fox, R., 2005. Bacterial and fungal diseases of garden plants. Microbiology Today 5, 60-63.

Frankland, A.W., Gregory, P.H., 1973. Allergenic and agricultural implications of airborne ascospores concentrations from a fungus, Didymella exitialis. Nature 245, 336-337. 
Ghasemi, A., Zahediasl, S. 2012. Normality tests for statistical analysis: A Guide for nonstatisticians. Int. J. Endocrinol. Metab. 10, 486-489.

Gonianakis, M., Neonakis, I., Darivianaki, E., Gonianakis, I., Bouros, D., Kontou-Fili, K., 2005. Airborne Ascomycotina on the island of Crete: Seasonal patterns based on an 8-year volumetric survey. Aerobiologia 21, 69-74.

Grinn-Gofroń, A., Strzelczak, A., 2009. Hourly predictive artificial neural network and multivariate regression tree models of Alternaria and Cladosporium spore concentrations in Szczecin (Poland). Int. J. Biometeorol. 53, 555-562.

Hampton, J.G., 1975. Studies on the diseases of wheat in New Zealand caused by Septoria and Tilletia spp., Lincoln College, Canterbury.

Harries, M.G., Lacey, J., Tee, R.D., Cayley, G.R., Taylor A.J., 1985. Didymella exitialis and late summer asthma. The Lancet 1, 1063-1066.

Hernández Trejo, F., Muñoz Rodríguez, A.F., Tormo-Molina, R., Silva Palacios, I., 2012. Airborne ascospores in Mérida (SW Spain) and the effect of rain and other meteorological parameters on their concentration. Aerobiologia 28, 13-26.

Hirst, J., 1952. An automatic volumetric spore trap. Ann. Appl. Biol. 39, 257-265.

Hirst, J., 1953. Changes in atmospheric spore content. Diurnal periodicity and the effects of weather. Trans. Br. Mycol. Soc. 36, 375-393.

Huang, Y.-J., Fitt, B.D.L., Jedryczka, M., Dakowska, S., West, J.S., Gladders, P., Steed, J.M., Li, Z.-Q., 2005. Patterns of ascospore release in relation to Phoma stem canker epidemiology in England (Leptosphaeria maculans) and Poland (Leptosphaeria biglobosa). Eur. J. Plant Pathol. 111, 263-277.

Ingold, C.T., 1971. Fungal spores. Their liberation and dispersal, Clarendon Press, Oxford.

Ingold, C.T., 1979. The biology of fungi, Hutchinson, London.

Isard, S.A., Gage, S.H., Comtois, P., Russo, J.M., 2005. Principles of the atmospheric pathway for invasive species applied to soybean rust. BioScience 55, 851-861. 
Jackson, F.A., 1984. Didymella, in: Wilken-Jensen, K., Gravesen, S. (Eds.), Atlas of moulds in Europe. ASK Publishing, Baarn, pp. 30.

Jäger, S., 2003. Plant taxonomy and nomenclature. Postęp Derm. Alergol. 20, 218-226.

Kaiser, W.J., Küsmenoglu, I., 1997. Distribution of mating types and the teleomorph of Ascochyta rabiei on chickpea in Turkey. Plant Dis. 81, 1284-1287.

Khan, T.N., Timmerman-Vaughan, G.M., Rubiales, D., Warkentin, T.D., Siddique, K.H.M., Erskine, W., Barbetti, M.J., 2013. Didymella pinodes and its management in field pea: Challenges and opportunities. Field Crops Res. 148, 61-77.

Khandelwal, A., 2001. Survey of aerospora by Rotorod Sampler in Lucknow, India: qualitative and quantitative assessment. Aerobiologia 17, 77-83.

Kirk, P.M., Cannon, P.F., David, J.C., Stalpers, J.A., 2004. Ainsworth and Bisby's dictionary of the fungi, Biddles Ltd., King’s Lynn.

Lacey, W.E., West, J., 2006. The air spora. A manual for catching and identifying airborne biological particles, Springer, Dordrecht.

Martínez Blanco, X., Tejera, L., Beri, Á., 2016. First volumetric record of fungal spores in the atmosphere of Montevideo City, Uruguay: a 2-year survey. Aerobiologia 32, 317-333.

Meredith, D.S., 1973. Significance of spore release and dispersal mechanisms in plant disease epidemiology. Annu. Rev. Phytopathol. 11, 313-342.

Miller, S.A., Rowe, R.C., Riedel, R.M., 2001. Gummy stem blight and black rot of cucurbits, Extension Fact Sheet, The Ohio State University, HYG-3126-96.

Morrow Brown, H., Jackson, F.A., 1985. Didymella, asthma and the weather. The Lancet 325, 1326-1327.

Newson, R., Strachan, D., Corden, J., Millington, W., 2000. Fungal and other spore counts as predictors of admissions for asthma in the Trent region. Occup. Environ. Med. 57, 786792. 
Nicolaisen, M., Justesen, A.F., Knorr, K., Wang, J., Pinnschmidt, H.O., 2014. Fungal communities in wheat grain show significant co-existence patterns among species. Fungal Ecol. 11, 145153.

Nilsson, S., Persson, S., 1981. Tree pollen spectra in the Stockholm region (Sweden), 1973-1980. Grana 20, 179-182.

O’Connor, D.J., Sadyś, M., Skjøth, C.A., Healy, D.A., Kennedy, R., Sodeau, J., 2014. Atmospheric concentrations of Alternaria, Cladosporium, Ganoderma and Didymella spores monitored in Cork (Ireland) and Worcester (England) during the summer of 2010. Aerobiologia 30, 397-411.

Oh, S.-Y., Fong, J.J., Park, M.S., Chang, L., Lim, Y.W., 2014. Identifying Airborne Fungi in Seoul, Korea Using Metagenomics. J. Microbiol. 52, 465-472.

Packe, G.E., Ayres, J.G., 1985. Asthma outbreak during a thunderstorm. The Lancet 2, 199-204.

Pakpour, S., Li, D.-W., Klironomos, J., 2015. Relationships of fungal spore concentrations in the air and meteorological factors. Fungal Ecol. 13, 130-134.

Pulimood, T.B., Corden, J.M., Bryden, C., Sharples, L., Nasser, S.M., 2007. Epidemic asthma and the role of the fungal mold Alternaria alternata. J. Allergy Clin. Immunol. 120, 610-617.

Stefansson, T.S., Hallsson, J.H., 2011. Analysis of the species diversity of leaf pathogens in Icelandic barley fields. Icel. Agric. Sci. 24, 13-22.

Quintero, E., Rivera-Mariani, F., Bolaños-Rosero, B., 2010. Analysis of environmental factors and their effects on fungal spores in the atmosphere of a tropical urban area (San Juan, Puerto Rico). Aerobiologia 26, 113-124.

Richardson, M.J., 1996. The occurrence of airborne Didymella spores in Edinburgh. Mycol. Res. $100,213-216$.

Sadyś, M., Strzelczak, A., Grinn-Gofroń, A., Kennedy, R. 2015. Application of redundancy analysis for aerobiological data. Int. J. Biometeorol. 59, 25-36. 
Sadyś, M., Adams-Groom, B., Herbert, R.J., Kennedy, R. 2016. Comparisons of fungal spore distributions using air sampling at Worcester, England (2006-2010). Aerobiologia 32, 619-634.

Salam, M.U., Galloway, J., Diggle, A.J., MacLeod, W.J., Maling, T., 2011. Predicting regional-scale spread of ascospores of Didymella pinodes causing ascochyta blight disease on field pea. Australasian Plant Pathol. 40, 640-647.

Sousa, L., Câmara Camacho, I., Grinn-Gofroń, A., Camacho, R., 2016. Monitoring of anamorphic fungal spores in Madeira region (Portugal), 2003-2008. Aerobiologia 32, 303-315.

Stępalska, D., Wołek, J., 2005. Variation in fungal spore concentrations of selected taxa associated to weather conditions in Cracow, Poland, in 1997. Aerobiologia 21, 43-52.

Stępalska, D., Wołek, J., 2009. Intradiurnal periodicity of fungal spores concentrations (Alternaria, Botrytis, Cladosporium, Didymella, Ganoderma) in Cracow, Poland. Aerobiologia 25, 333-340.

Stępalska, D., Grinn-Gofroń, A., Piotrowicz, K., 2012. Occurrence of Didymella ascospores in western and southern Poland in 2004-2006. Aerobiologia 28, 153-159.

Thibaudon, M., Sauleau, E.-A., Oliver, G., Poirot, A., Heaulme, R., Harscoat, S., de Blay, F., 2014. Moisissures - Orages - Asthme. Rev. Fr. Allergol. 54, 124-126.

Trapero-Casas, A., Navas-Cortés, J.A., Jiménez-Díaz, R.M., 1996. Airborne ascospores of Didymella rabiei as a major primary inoculum for Ascochyta blight epidemics in chickpea crops in southern Spain. Eur. J. Plant Pathol. 102, 237-245.

von Wahl, P.-G., Kersten, W., 1991. Fusarium and Didymella - neglected spores in the air. Aerobiologia 7, 111-117.

West, J.S., Kimber, R.B.E., 2015. Innovations in air sampling to detect plant pathogens. Ann. Appl. Biol. 166, 4-17.

Zar, J.H., 1984. Biostatistical analysis, Prentice Hall, New Jersey.

Zhang, Y., Crous, P.W., Schoch, C.L., Hyde, K.D., 2012. Pleosporales. Fungal Divers. 53, 1-221. 


\section{Figure captions}

Fig. 1 Didymella ascospores from air samples collected at Worcester, UK under $\times 1000$ magnification (A, B), and at $\times 400$ magnification (C). The arrow points at hyaline Didymella ascospores.

Fig. 2 Variations in Didymella ascospore seasons between examined years at Worcester, UK. Season dynamics comprise the following fractions: 1\%, 5\%, 25\%, 50\% (upright line), 75\%, 95\% and $99 \%$.

Fig. 3 (A) Overall variations in Didymella ascospore hourly distribution at Worcester, UK and based on 5-y spore seasons pooled together $(n=9,381)$. The negative error bars were the result of subtraction between the first quartile (the middle value between the smallest number and the median of the data set) and the minimum value, while the positive error bars were the result of subtraction between the maximum value and the third quartile (the middle value between the median and the highest value of the data set). Results were transformed and given on the $\log 10$ scale from noon to noon. (B) The multivariate regression tree shows the dependence of the Didymella ascospore concentrations on the time of day.

Fig. 4 Mean hourly distributions of Didymella ascospores depending on: (A) the spore season/year, (B) presence or absence of rain, (C) amount of rainfall, (D) relative humidity, (E) maximum temperature, and (F) wind speed registered within $24 \mathrm{~h}$ at Worcester, UK. The ascospore concentrations are shown from noon to noon. Applied meteorological parameter thresholds were based on daily mean and daily cumulative (in case of rainfall) values.

Fig. 5 Daily changes in Didymella ascospore concentration on: (A) dry days followed by rainy; (B) on rainy days followed by dry; (C) on a single rainy day preceded and proceeded by 3 dry days. 
Figure 2
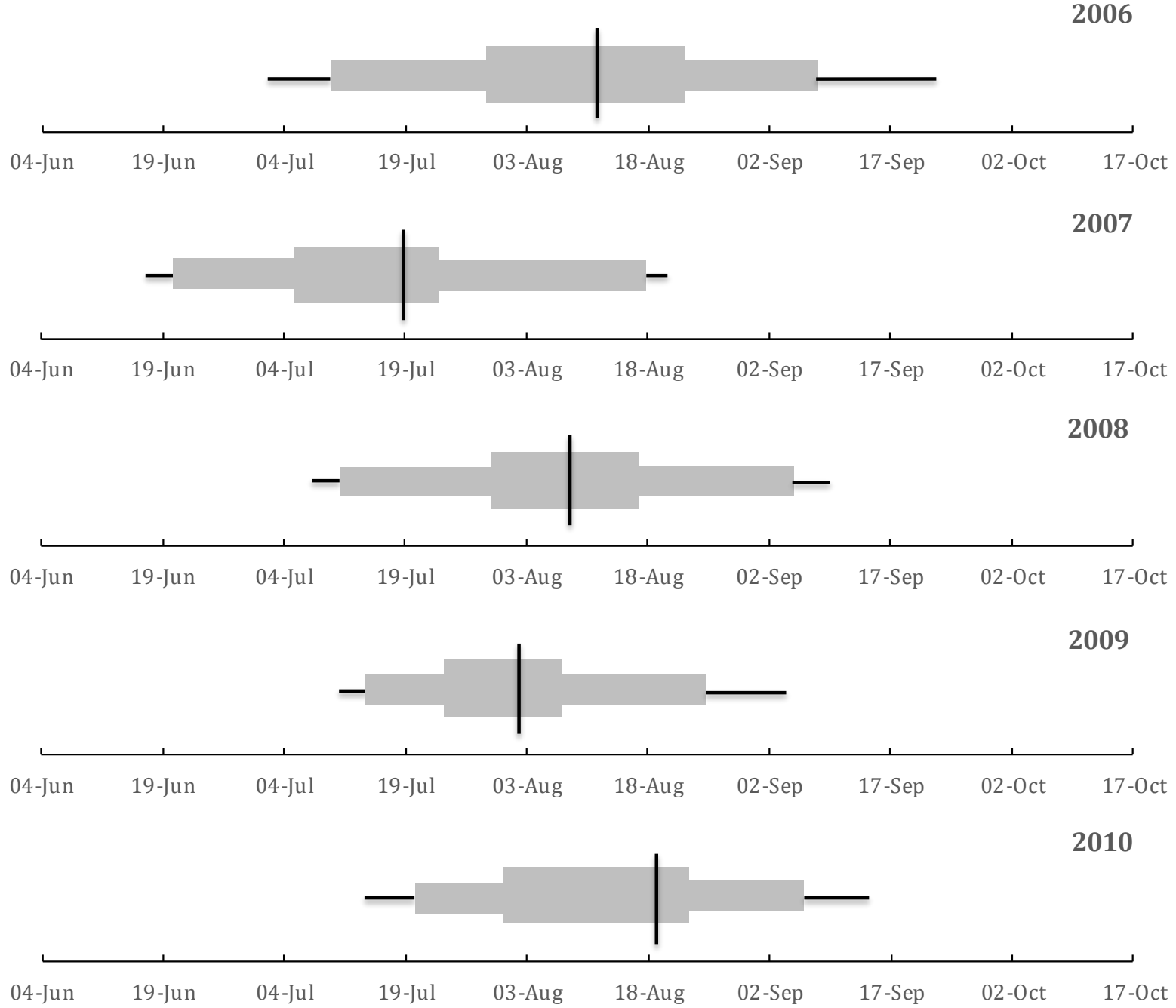
Figure 3

160000

150000

140000

130000

120000

110000

क 100000

ฐ 90000

\& 80000

○ 70000

ผ 60000

50000

40000

30000

20000

10000

七ே宁号

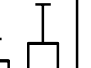

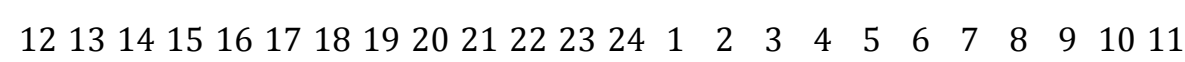

Hour

A

B

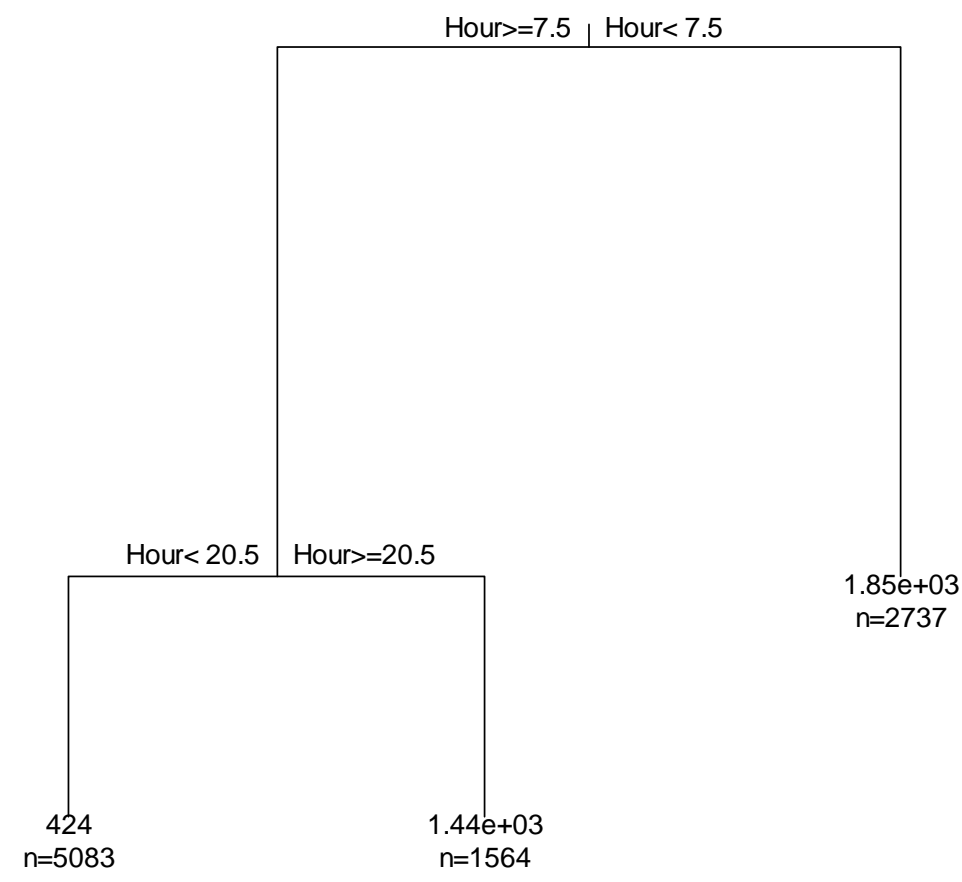

Error : 0.967 CV Error : 0.976 SE : 0.111 


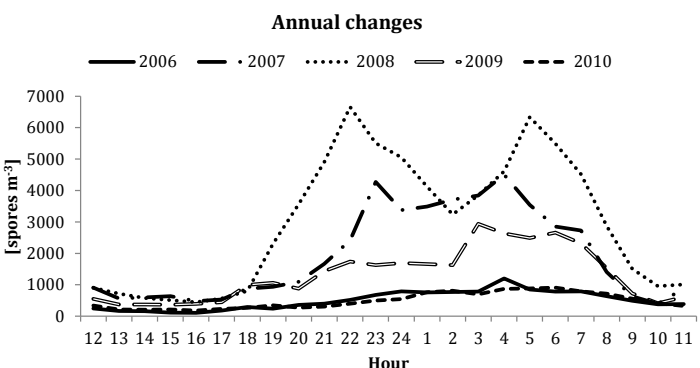

Amount of rainfall

$\longrightarrow<=5.00 \mathrm{~mm} \quad-\quad-5.00<=10.00 \mathrm{~mm}$

- $-\boldsymbol{-} 10.00<=15.00 \mathrm{~mm} \cdots \cdots \cdot 15.00<=20.00 \mathrm{~mm}$

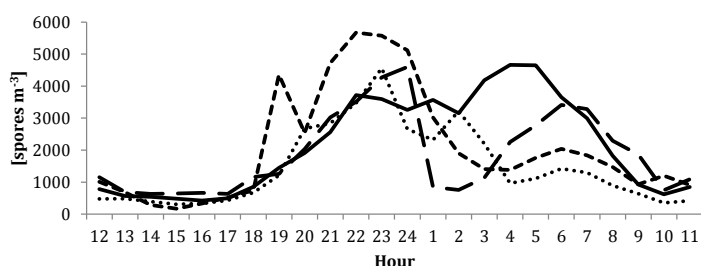

Maximum temperature

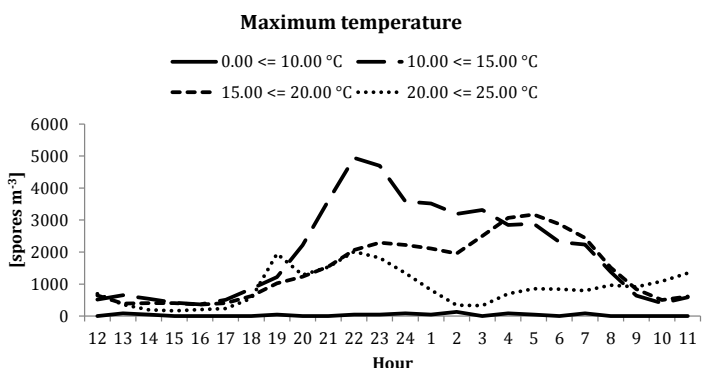

A

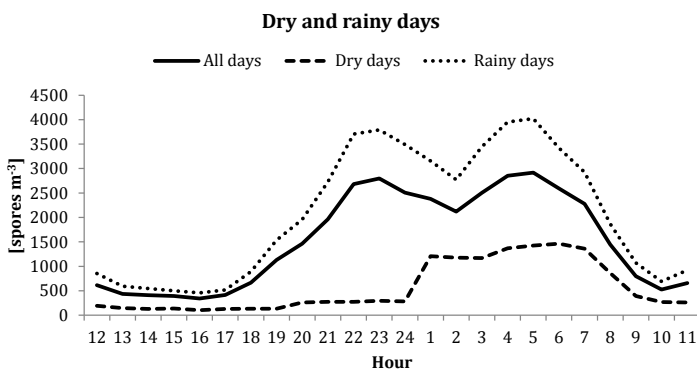

C

Relative humidity

D

- $40.00<=55.00 \%$ - $-55.00<=70.00 \%$

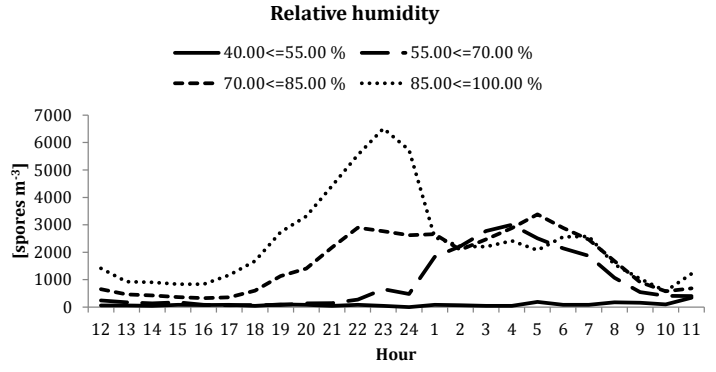

E

Wind speed

$\mathbf{F}$

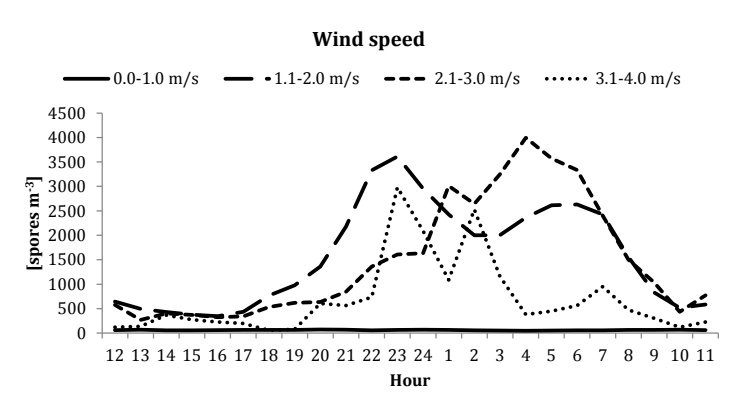

B

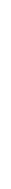

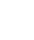




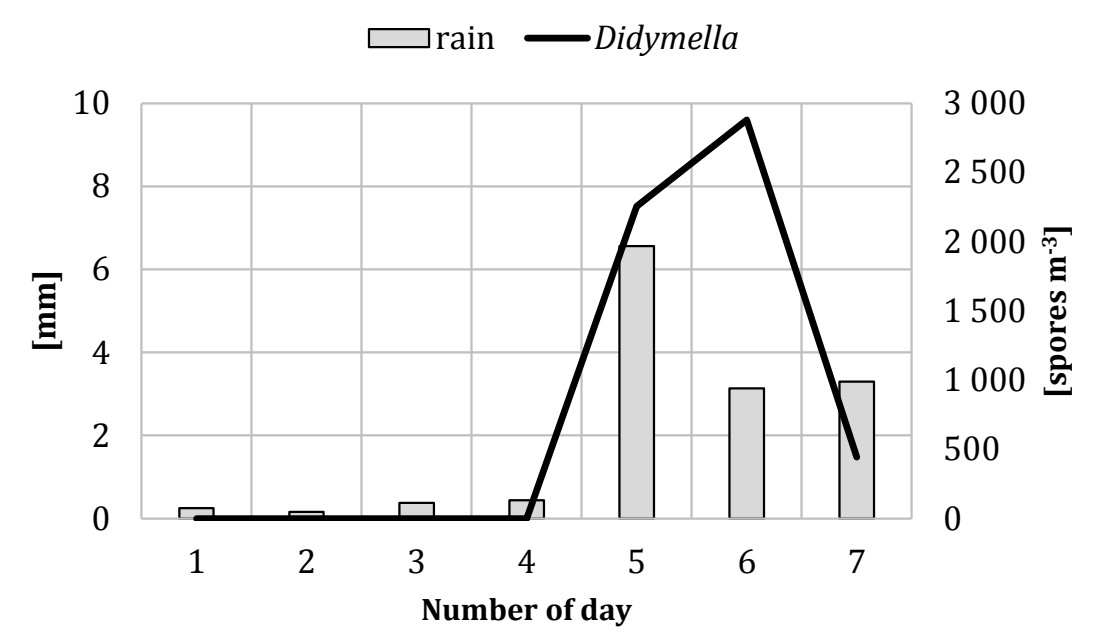

A

B
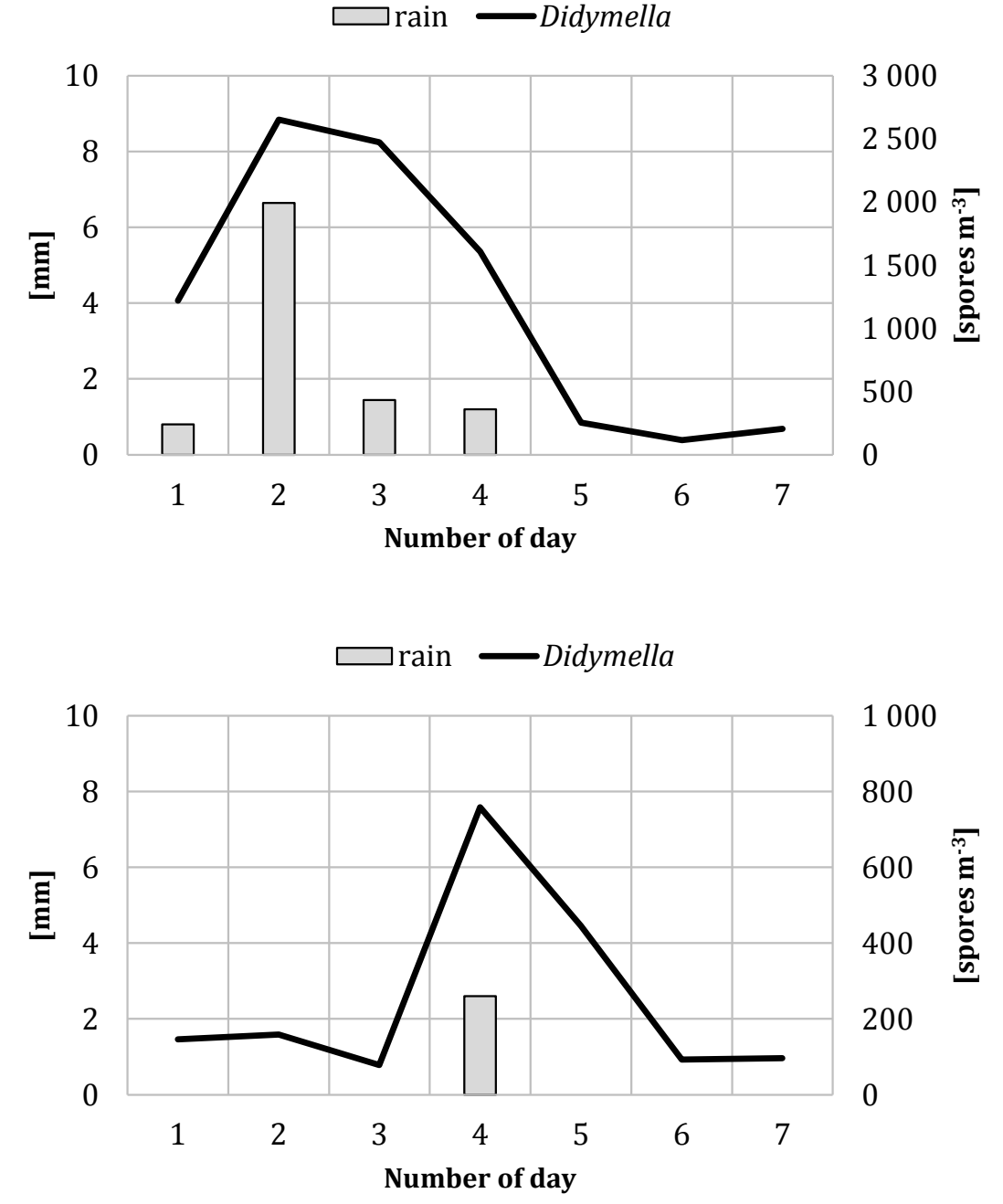

C 
Table $1 p$ values from ANOVA Kruskal-Wallis test (2-tailed) between examined years. Hourly concentrations values of Didymella ascospores were used.

\begin{tabular}{rrrrrr}
\hline Year & 2006 & 2007 & 2008 & 2009 & 2010 \\
\hline 2006 & & $\mathbf{0 . 0 0}^{*}$ & $\mathbf{0 . 0 0}^{*}$ & $\mathbf{0 . 0 1}^{*}$ & $n s$ \\
2007 & $\mathbf{0 . 0 0}^{*}$ & & $n s$ & $n s$ & $\mathbf{0 . 0 0}^{*}$ \\
2008 & $\mathbf{0 . 0 0}^{*}$ & $n s$ & & $n s$ & $\mathbf{0 . 0 0}^{*}$ \\
2009 & $\mathbf{0 . 0 1}^{*}$ & $n s$ & $n s$ & & $\mathbf{0 . 0 1}^{*}$ \\
2010 & $n s$ & $\mathbf{0 . 0 0}^{*}$ & $\mathbf{0 . 0 0}^{*}$ & $\mathbf{0 . 0 1}^{*}$ & \\
\hline
\end{tabular}

Level of statistical significance: $\left({ }^{*}\right) p \leq 0.05,\left({ }^{* *}\right) p \leq 0.01,\left({ }^{* * *}\right) p \leq 0.001, n s-$ not significant. 
Table 2 Variations in the peak occurrence calculated using circular statistics

\begin{tabular}{lllllll}
\hline Factor & 2006 & 2007 & 2008 & 2009 & 2010 & $2006-2010$ \\
\hline Mean angle of the peak & $152^{\circ}$ & $75^{\circ}$ & $98^{\circ}$ & $120^{\circ}$ & $148^{\circ}$ & $114^{\circ}$ \\
Mean time of the peak & $10: 08 \mathrm{~h}$ & $05: 00 \mathrm{~h}$ & $06: 32 \mathrm{~h}$ & $08: 00 \mathrm{~h}$ & $09: 52 \mathrm{~h}$ & $07: 36 \mathrm{~h}$ \\
Angular deviation & $79^{\circ}$ & $76^{\circ}$ & $73^{\circ}$ & $73^{\circ}$ & $78^{\circ}$ & $76^{\circ}$ \\
Angular deviation & $5 \mathrm{~h} 16 \mathrm{~m}$ & $5 \mathrm{~h} 4 \mathrm{~m}$ & $4 \mathrm{~h} 52 \mathrm{~m}$ & $4 \mathrm{~h} 52 \mathrm{~m}$ & $5 \mathrm{~h} 12 \mathrm{~m}$ & $5 \mathrm{~h} 4 \mathrm{~m}$ \\
\hline
\end{tabular}


Table 3 The results of sign test for the comparison of changes in diurnal pattern of Didymella ascospores

\begin{tabular}{lcrrrrrr}
\hline Factor & Year & 2006 & 2007 & 2008 & 2009 & 2010 & $2006-10$ \\
\hline +/- rainfall & $Z$ & 4.69 & 4.69 & 4.69 & 4.69 & 3.88 & 10.50 \\
& $p$ & $\mathbf{0 . 0 0}^{*}$ & $\mathbf{0 . 0 0}^{*}$ & $\mathbf{0 . 0 0 *}$ & $\mathbf{0 . 0 0}^{*}$ & $\mathbf{0 . 0 0}^{*}$ & $\mathbf{0 . 0 0}^{*}$ \\
\hline
\end{tabular}

Level of statistical significance: $\left({ }^{*}\right) p \leq 0.05,\left({ }^{* *}\right) p \leq 0.01,\left({ }^{* * *}\right) p \leq 0.001, n s-$ not significant. 
Table 4 The results of Friedman test for the comparison of changes in diurnal pattern of Didymella ascospores

\begin{tabular}{lrrrrrrr}
\hline Factor & Year & 2006 & 2007 & 2008 & 2009 & 2010 & $2006-10$ \\
\hline rainfall $[\mathrm{mm}]$ & $\chi^{2}$ & 47.41 & 18.20 & 8.85 & 34.55 & 25.37 & 45.17 \\
& $p$ & $\mathbf{0 . 0 0}$ & $\mathbf{0 . 0 0}$ & $\mathbf{0 . 0 3}$ & $\mathbf{0 . 0 0}$ & $\mathbf{0 . 0 0}$ & $\mathbf{0 . 0 0}$ \\
\hline relative humidity $[\%]$ & $\chi^{2}$ & 39.80 & 66.65 & 55.35 & 53.25 & 63.91 & 264.80 \\
& $p$ & $\mathbf{0 . 0 0}^{*}$ & $\mathbf{0 . 0 0}^{*}$ & $\mathbf{0 . 0 0}^{*}$ & $\mathbf{0 . 0 0}^{*}$ & $\mathbf{0 . 0 0}^{*}$ & $\mathbf{0 . 0 0}^{*}$ \\
\hline max. temperature $\left[{ }^{\circ} \mathrm{C}\right]$ & $\chi^{2}$ & 43.85 & 64.97 & 61.35 & 51.95 & 37.18 & 218.73 \\
& $p$ & $\mathbf{0 . 0 0}^{*}$ & $\mathbf{0 . 0 0}^{*}$ & $\mathbf{0 . 0 0}^{*}$ & $\mathbf{0 . 0 0}^{*}$ & $\mathbf{0 . 0 0}^{*}$ & $\mathbf{0 . 0 0}^{*}$ \\
\hline wind speed $\left[\mathrm{m} \mathrm{s}^{-1}\right]$ & $\chi^{2}$ & 37.55 & 51.60 & 66.05 & 65.25 & 65.15 & 252.21 \\
& $p$ & $\mathbf{0 . 0 0}^{*}$ & $\mathbf{0 . 0 0}^{*}$ & $\mathbf{0 . 0 0}^{*}$ & $\mathbf{0 . 0 0}^{*}$ & $\mathbf{0 . 0 0}^{*}$ & $\mathbf{0 . 0 0}^{*}$ \\
\hline
\end{tabular}

Level of statistical significance: $\left({ }^{*}\right) p \leq 0.05,\left({ }^{* *}\right) p \leq 0.01,\left({ }^{* * *}\right) p \leq 0.001, n s-$ not significant. 